\title{
Modeling volcanic ash resuspension - application to the 14-18 October 2011 outbreak episode in central Patagonia, Argentina
}

\author{
A. Folch ${ }^{1}$, L. Mingari ${ }^{2,3,5}$, M. S. Osores ${ }^{3,4,5}$, and E. Collini ${ }^{2,5}$ \\ ${ }^{1}$ Barcelona Supercomputing Center - Centro Nacional de Supercomputación (BSC-CNS), Barcelona, Spain \\ ${ }^{2}$ Servicio de Hidrografía Naval (SHN), Buenos Aires, Argentina \\ ${ }^{3}$ Consejo Nacional de Investigaciones Científicas y Técnicas (CONICET), Buenos Aires, Argentina \\ ${ }^{4}$ Comisión Nacional de Actividades Espaciales (CONAE), Buenos Aires, Argentina \\ ${ }^{5}$ Servicio Meteorológico Nacional (SMN), Buenos Aires, Argentina
}

Correspondence to: A. Folch (arnau.folch@bsc.es)

Received: 29 July 2013 - Published in Nat. Hazards Earth Syst. Sci. Discuss.: 6 September 2013

Revised: 2 December 2013 - Accepted: 4 December 2013 - Published: 17 January 2014

\begin{abstract}
Volcanic fallout deposits from the June 2011 Cordón Caulle eruption on central Patagonia were remobilized in several occasions months after their emplacement. In particular, during 14-18 October 2011, an intense outbreak episode generated widespread volcanic clouds that were dispersed across Argentina, causing multiple impacts in the environment, affecting the air quality and disrupting airports. Fine ash particles in volcanic fallout deposits can be resuspended under favorable meteorological conditions, particularly during strong wind episodes in arid environments with low soil moisture and poor vegetation coverage. As opposed to eruption-formed ash clouds, modeling of resuspensionformed ash clouds has received little attention. In consequence, there are no emission schemes specially developed and calibrated for resuspended volcanic ash, and few operational products exists to model and forecast the formation and dispersal of resuspension ash clouds. Here we implement three dust emission schemes of increasing complexity in the FALL3D tephra dispersal model and use the 1418 October 2011 outbreak episode as a model test case. We calibrate the emission schemes and validate the results of the coupled WRF-ARW (Weather Research and Forecasting Advanced Research WRF)/FALL3D modeling system using satellite imagery and measurements of visibility (a quantity related to total suspended particle concentration at the surface) and particulate matter $\left(\mathrm{PM}_{10}\right)$ concentration at several meteorological and air quality stations located at Argentina and Uruguay. Our final goal is to test the capability of the
\end{abstract}

modeling system to become, in the near future, an operational forecast product for volcanic ash resuspension events.

\section{Introduction}

Resuspension and dispersal of volcanic ash by wind is of concern to human health and the environment (Baxter, 1999; Wilson et al., 2012). Micron-size ash particles suspended at low atmospheric levels deteriorate the quality of air and cause severe impacts on the local population and animals, causing irritation of mucosae, chronic respiratory symptoms resulting from inhalation of ash, and dispersion of toxic chemicals (see Baxter, 1999). Other hazards include disruption to ground transportation systems and airports (see Guffanti et al., 2009). All these impacts can occur far away from the original deposit region because, like dust clouds, resuspended ash clouds can be dispersed over large distances. The lift of ash and subsequent formation of clouds is enhanced under particular meteorological (such as strong winds and surface friction velocities) and ambient (such as low soil moisture, no vegetation) conditions, and can occur in both fresh and relic ash fallout deposits. For example, favorable meteorological conditions occurred during 20-21 September 2003 resulted in continuous resuspension of relic volcanic ash from the Katmai volcano and the formation of ash clouds that were transported up to $230 \mathrm{~km}$ into the Gulf of Alaska, affecting operations at the Kodiak Airport (Hadley et al., 2004). Other examples include resuspension of ash from 
fresh deposits of Mount St. Helens in the US (Hobbs et al., 1983), Soufriere Hills in Montserrat (Hincks et al., 2006), Mount Hudson in the southern Argentinean Patagonia (Wilson et al., 2011), Eyjafjallajökull in Iceland (Thorsteinsson et al., 2012; Leadbetter et al., 2012), and Cordón Caulle in the central Argentinean Patagonia, which is addressed in this paper.

Modeling of atmospheric dispersal and sedimentation of ash clouds from volcanic eruptions has been an active topic of research during the last two decades, and gained heightened interest in the aftermath of the major civil aviation disruptions following the 2010 Eyjafjallajökull and the 2011 Cordón Caulle eruptions. Several Volcanic Ash Transport and Dispersion Models (VATDM) (e.g., Folch, 2012) run operationally at the Volcanic Ash Advisory Centers (VAACs) and other institutions for forecasting purposes, and the underlaying modeling strategies are being substantially reviewed and improved (Bonadonna et al., 2012). In contrast, modeling of resuspended ash clouds has received little attention. This is surprising because, even if potentially less hazardous, resuspension-formed clouds can also trigger substantial impacts (see section 4). In fact, modeling of resuspended ash has been recognized as a research priority during a recent joint WMO (World Meteorological Organization)-VAAC modeling workshop (NOAA, Washington DC, 5-9 November 2012). The examples in literature regarding modeling of resuspended ash clouds are very scarce. Barsotti et al. (2010) proposed a simple fit based on data from Hincks et al. (2006) to estimate resuspended $\mathrm{PM}_{10}$ surface concentrations at various populated locations around the Etna volcano. More recently, Leadbetter et al. (2012) modeled resuspension events form the 2010 Eyjafjallajökull deposits using the UK Met Office Lagrangian dispersion model NAME-III (Numerical Atmospheric dispersion Modeling Environment). Given the similarities between volcanic ash and mineral dust, Leadbetter et al. (2012) considered a simple dust emission scheme to compute the mass flux of resuspended ash depending on the wind friction velocity and the occurrence of precipitation. This has been used by the London VAAC/UK Met Office to provide an operational warning forecast service for resuspended ash to IMO (Icelandic Met Office).

The objective of this paper is to test different dust emission schemes of increasing complexity for implementation in volcanic ash transport models. To this purpose, we implement three different schemes in the FALL3D model (Costa et al., 2006; Folch et al., 2009) and consider the Cordón Caulle 14-18 October 2011 outbreak episode as a test case. We use a meteorological station located in Buenos Aires (1380 $\mathrm{km}$ from the volcano) to calibrate the emission of ash. This is necessary because uncertainties exist in both source strength parameters and formulation, including that the emission schemes have been originally developed for mineral dust rather than for volcanic ash, and poor constraints on the properties and grain size distribution of ash particles along the deposit. After calibrating, we compare the model results with satellite retrievals and particulate matter surface concentrations inferred from observations at different meteorological and air quality stations across Argentina. The final goal is to test the modeling strategy before its implementation as an operational forecast product at the Argentinean National Meteorological Service (SMN) and Buenos Aires VAAC.

\section{Previous considerations on modeling volcanic ash resuspension}

Modeling of volcanic ash resuspension requires the implementation of emission schemes in VATDMs. Emission schemes give the mass flux of resuspended (ash) particles depending on meteorological conditions, soil moisture, terrain roughness, and characteristics of the fallout deposit (size and density of particles, grain-size distribution, deposit thickness). Typically, soil moisture is obtained from the Numerical Weather Prediction (NWP) model driving the VATDM (WRF-ARW in our case). This can introduce an unknown uncertainty as NWP models do not include updated information about recent fallout deposits, which can substantially alter moisture and roughness of the original soil. On the other hand, fallout deposits are heterogeneous, introducing a second source of uncertainty regarding granulometric properties. Heterogeneities in grain-size distribution and particle properties exist because the variation of settling velocity with particle size and density (causing strong granulometric variations along the dispersal axis), occurrence of different eruptive phases (e.g., variable eruption rates, column heights, degree of magma fragmentation, etc.), or transport under unsteady heterogeneous wind fields. Moreover, even if a fallout deposit is well characterized through a dedicated field campaign, information is rarely available in a regular grid, but rather across transects or along the most accessible deposit parts (e.g., along roads). It follows that, from a modeling perspective and in practical terms, an option to obtain the granulometric characteristics at all deposit grid points is to run a preliminary simulation for the fallout using the total grain size distribution, typically reconstructed from field data.

\section{Dust emission schemes}

Saltation impact represents the most effective mechanism for resuspension of smaller-size particles in soils (Shao et al., 1993). When the intensity of wind blowing across a granular soil exceeds a certain threshold, grain particles begin to saltate. Experiments with sand-sized particles show that the impact of saltating mid-size grains (larger than about $50 \mu \mathrm{m}$ ) when falling back to ground breaks the cohesive forces of smaller particles, enhancing their suspension. For this reason, the emission rate (vertical flux of particles), defined as the mass emitted per unit of area and time, strongly depends on the horizontal (saltation) flux of larger particles. In recent years, various emission schemes for mineral dust have been 
proposed and implemented in atmospheric transport models to simulate long-range transport and deposition of mineral dust. This section summarizes different dust emission schemes that we will test for volcanic ash. We follow an approach similar to that of Darmenova et al. (2009) and Kang et al. (2012), who tested different dust emission schemes in the WRF and WRF-Chem models respectively.

\subsection{Threshold friction velocity}

The friction velocity $u_{*}$ is a reference velocity used in surface boundary layer theory to scale the shear stress of a fluid, assumed proportional to the square of the mean velocity. The threshold friction velocity, defined as the wind friction velocity at which soil erosion initiates (Greeley and Iversen , 1985), depends on physical properties of soil particles (size and density) and on surface conditions such as soil moisture and roughness. Soil moisture reinforces soil particle cohesion and therefore inhibits erosion and resuspension. The presence of rough elements on the ground (e.g., non erodible rocks or vegetation) also decreases the emission rate of particles because the elements act as wind shelters and absorb part of the momentum of the wind, leading to a decrease of wind shear stress acting on the erodible surface. A precise quantification of the friction velocity is challenging and requires data on soil properties and meteorological conditions, which may be unavailable on a local scale.

Simple dust emission schemes assume a constant threshold friction velocity over the region of interest regardless of the particle size. For example, Leadbetter et al. (2012) modeled the resuspension of ash after the 2010 Eyjafjallajökull eruption in Iceland assuming a threshold friction velocity of $0.4 \mathrm{~m} \mathrm{~s}^{-1}$ for all particle diameters in the range $1-10 \mu \mathrm{m}$ combined with a precipitation rate cutoff of $0.01 \mathrm{~mm} \mathrm{hr}^{-1}$. The cutoff accounts for a critical soil moisture above which the emission of particles is assumed to be inhibited. However, the constant friction velocity approach can be inadequate over large areas because particle properties and soil characteristics are likely to vary substantially in space. For example, in the particular case of volcanic deposits, a decrease in the mean particle size is expected at more distal locations. In order to account for heterogeneous particle and soil characteristics, the threshold friction velocity $u_{* t}$ can be expressed at each point as (Shao, 2001)

$u_{* t}(d, w, \lambda)=u_{* t s}(d) f_{w}(w) f_{\lambda}(\lambda)$,

where $u_{* t s}(d)$ is the threshold friction velocity on a bare dry surface for particles of size $d$ (for irregular particles $d$ is assumed to be the equivalent particle diameter), and $f_{w}(w)$ and $f_{\lambda}(\lambda)$ are correction functions for soil moisture $w$ and surface roughness $\lambda$, respectively $\left(f_{w}(w) \geq 1\right.$ and $\left.f_{\lambda}(\lambda) \geq 1\right)$. A number of experimental and theoretical studies have determined parameterizations for threshold friction velocities on bare dry surfaces. Marticorena and Bergametti (1995) fitted experimental data obtained in wind tunnels by Iversen and White (1982) for various particle densities (from 210 to $1135 \mathrm{~kg} \mathrm{~m}^{-3}$ ) and diameters (from 12 to $1290 \mu \mathrm{m}$ ), and derived the following expression for $u_{* t s}$ depending on particle size and density:

$u_{* t s}= \begin{cases}\frac{0.129 K}{\left(1.928 R e^{0.092}-1\right)^{0.5}} & 0.03<R e \leq 10 \\ 0.129 K\left(1-0.0858 e^{-0.0617(R e-10)}\right) & R e>10\end{cases}$

with $K=\sqrt{\frac{\rho_{p} g d}{\rho_{a}}\left(1+\frac{0.006}{\rho_{p} g d^{2.5}}\right)}$ and $R e=1331 \times d^{1.56}$ (the lower bound of the fit corresponds to particles of $\approx 10 \mu \mathrm{m}$ in size). In the expressions above, $\rho_{p}$ and $\rho_{a}$ are particle and air densities (expressed in $\mathrm{g} \mathrm{cm}^{-3}$ ), $g$ is gravity (in $\mathrm{cm} \mathrm{s}^{-2}$ ), $d$ is the particle size (in cm), $R e$ is the Reynolds number parameterized as a function of the particle size, and $u_{* t s}$ is given in $\mathrm{cm} \mathrm{s}^{-1}$. In turn, Shao and $\mathrm{Lu}$ (2000) derived an expression for $u_{* t s}$ considering spherical particles with a cohesion force proportional to particle size:

$u_{* t s}=\sqrt{0.0123\left(\frac{\rho_{p} g d}{\rho_{a}}+\frac{\gamma}{\rho_{a} d}\right)}$,

where $\gamma$ is a parameter ranging between $1.65 \times 10^{-4}$ and $5 \times 10^{-4} \mathrm{~kg} \mathrm{~s}^{-2}$ (a value of $3 \times 10^{-4} \mathrm{~kg} \mathrm{~s}^{-2}$ is assumed here).

Using experimental data from literature, Fecan et al. (1999) parameterized the increase in the threshold friction velocity due to soil moisture in arid and semi-arid regions and derived the following expression:

$f_{w}(w)= \begin{cases}1 & w_{\mathrm{g}} \leq w^{\prime}(\text { dry soil) } \\ \sqrt{1+1.21\left(w_{\mathrm{g}}-w^{\prime}\right)^{0.68}} & w_{\mathrm{g}}>w^{\prime}(\text { wet soil) },\end{cases}$

where $w^{\prime}$ is the maximum amount of water that can be absorbed (depending on soil texture) and $w_{\mathrm{g}}$ is the gravimetric soil moisture (water to soil bulk mass ratio), $w_{\mathrm{g}}=w \rho_{\mathrm{w}} / \rho_{\mathrm{b}}$ with $\rho_{\mathrm{w}}$ and $\rho_{\mathrm{b}}$ being the water and soil bulk densities respectively, and $w$ is the volumetric soil moisture in \% (water to soil bulk volume ratio). The values of $w$ can be obtained from a NWP model. When the gravimetric soil moisture content $w_{\mathrm{g}}$ is close to but smaller than $w^{\prime}$ (dry soil), interparticle capillary forces are not strong enough to increase the erosion threshold significantly. The value of $w^{\prime}$ ranges from $0 \%$ for sand to $\approx 30 \%$ for pure clay (Fecan et al., 1999). It is difficult to give a value of $w^{\prime}$ for volcanic fallout deposits because the amount of water that can be absorbed strongly depends on porosity which, in turn, depends on variable factors controlling tephra formation (e.g., magma rehology, degree of fragmentation, amount of volatiles in magma, etc.). In this study we assume that $w^{\prime}=10 \%$. Figure 1 shows the dependency of the threshold friction velocity $u_{* t}$ on particle size with and without soil moisture correction. Note that particles in the range of 30-200 $\mu \mathrm{m}$ are more likely suspended.

On the other hand, several parameterizations have been proposed for the so-called drag partition coefficient, the inverse of $f_{\lambda}(\lambda)$ (e.g., Marticorena and Bergametti, 1995), depending on the roughness length over a smooth surface and 


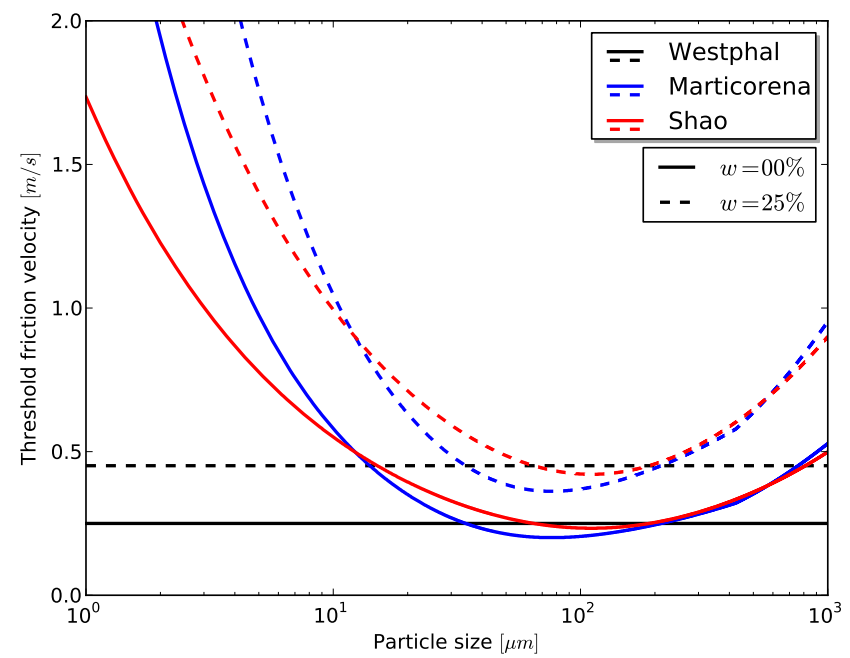

Fig. 1. Dependency of the threshold friction velocity $u_{* t}$ on particle size (in $\mu \mathrm{m}$ ) according to Shao and $\mathrm{Lu}$ (2000) (red line, Eq. 3) and Marticorena and Bergametti (1995) (blue line, Eq. 2). Solid lines are without moisture correction $(w=0)$. Dotted lines show the effect of moisture using Eq. (4) with $w=25 \%$ and $w^{\prime}=10 \%$. For comparison, the solid black line shows the constant threshold friction velocity, $u_{* t s}=0.25 \mathrm{~m} \mathrm{~s}^{-1}$, used in WE scheme and the dotted black line its correction when a moisture of $w=25 \%$ is considered.

the aeolian roughness length. However, it is very difficult to assess these parameters in the case of ash fallout deposits. An obvious difficulty is that the deposition of ash modifies the underlying surface (to an extent that depends on the thickness of deposit) affecting any information embedded in the land modules of NWP models (e.g., roughness length). For this reason the influence of terrain roughness on the threshold friction velocity will not be considered in this study.

\subsection{Horizontal (saltation) flux}

The horizontal flux of saltating particles, i.e., the stream-wise flux of saltating particles integrated along the vertical, measures the "intensity" of saltation, which strongly affects the emission rate of smaller-size particles. Following the theory of saltation and experimental results from Owen (1964), Shao et al. (1993) proposed the following parameterization:

$F_{\mathrm{H}}\left(d_{\mathrm{S}}\right)= \begin{cases}0 & u_{*}<u_{* t}\left(d_{\mathrm{s}}\right) \\ c_{\mathrm{o}} \frac{\rho_{a} u_{*}^{3}}{g}\left(1-\frac{u_{* t}^{2}\left(d_{\mathrm{s}}\right)}{u_{*}^{2}}\right) & u_{*} \geq u_{* t}\left(d_{\mathrm{s}}\right),\end{cases}$

where $F_{\mathrm{H}}$ is the horizontal (saltation) flux (units of $\mathrm{kg} \mathrm{m}^{-1} \mathrm{~s}^{-1}$ ) of saltating particles of size $d_{\mathrm{s}}$, and $c_{\mathrm{o}}$ is an empirical dimensionless constant close to 1 . A similar expression was proposed by Marticorena and Bergametti (1995) and Marticorena et al. (1997) after the seminal work of White (1979):

$F_{\mathrm{H}}\left(d_{\mathrm{S}}\right)= \begin{cases}0 & u_{*}<u_{* t}\left(d_{\mathrm{S}}\right) \\ c_{\mathrm{w}} \frac{\rho_{a} u_{*}^{3}}{g}\left(1+\frac{u_{* t}\left(d_{\mathrm{s}}\right)}{u_{*}}\right)\left(1-\frac{u_{* t}^{2}\left(d_{\mathrm{s}}\right)}{u_{*}^{2}}\right) & u_{*} \geq u_{* t}\left(d_{\mathrm{s}}\right),\end{cases}$ with $c_{\mathrm{W}}=2.61$ according to the original wind tunnel experiments (White, 1979) and $c_{\mathrm{W}} \approx 1$ according to successive corrections (Marticorena et al., 1997).

\subsection{Vertical flux (emission rate)}

The simplest dust emission parameterizations depend only on meteorological conditions (typically on a power of the friction velocity). For example, Westphal et al. (1987) measured the vertical flux of aerosol dust particles $(<10 \mu \mathrm{m}$ radius) from sandy, loamy, and clay soils depending on the friction velocity and obtained the following least squares fit:

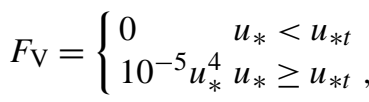

where $F_{\mathrm{V}}$ is the vertical flux (in $\mathrm{kg} \mathrm{m}^{-2} \mathrm{~s}^{-1}$ ), occurring only above a (constant) threshold friction velocity of $u_{* t}=$ $0.3 \mathrm{~m} \mathrm{~s}^{-1}$ in the particular experiment of Westphal et al. (1987). An important limitation of Eq. (7) is that the vertical flux does not depend on particle size or soil moisture. Although very simplistic, this parameterization can be useful when information on soil characteristics (e.g., particle sizes and densities, moisture, roughness, etc.) is poorly constrained or unavailable.

A slightly more sophisticated approach consists of modeling the emission rate as a function of the difference between the friction velocity and the threshold friction velocity. This embeds all the information on soil properties within the threshold friction velocity and allows one to compute fluxes depending on particle size. For example, from the parameterization in Marticorena et al. (1997b):

$F_{\mathrm{V}}(d)= \begin{cases}0 & u_{*}<u_{* t}(d) \\ \frac{K \rho_{a} u_{*}}{g}\left(u_{*}^{2}-u_{* t}^{2}(d)\right) & u_{*} \geq u_{* t}(d),\end{cases}$

where $K$ is a soil texture coefficient equal to $K=5.4 \times$ $10^{-4} \mathrm{~m}^{-1}$ from the experiments of Gillette et al. (1997). This parameterization has been used, among others, by Draxler et al. (2001) to simulate $\mathrm{PM}_{10}$ concentrations from dust storms using the HYSPLIT model.

Finally, more sophisticated emission schemes consider particle-particle interaction by saltation bombardment and, in some cases, by aggregate disintegration (e.g., Shao, 2001). Shao et al. (1993) considered that the vertical flux (emission rate) of particles of size $d$ caused by the saltation bombardment of particles of size $d_{\mathrm{s}}\left(d_{\mathrm{s}} \geq d\right)$ is proportional to the horizontal flux of saltating particles:

$F_{\mathrm{V}}\left(d, d_{\mathrm{s}}\right)=\frac{\alpha\left(d, d_{\mathrm{s}}\right)}{u_{* t}^{2}(d)} F_{\mathrm{H}}\left(d_{\mathrm{s}}\right)$,

where $\alpha$ (units of $\mathrm{m} \mathrm{s}^{-2}$ ) is a coefficient of blasting efficiency determined experimentally (Shao and Leslie, 1997; Shao, 2001):

$\alpha\left(d, d_{\mathrm{s}}\right)=\left(0.6 \log \left(d_{\mathrm{s}}\right)+1.6\right) \exp (-140 d)$ 


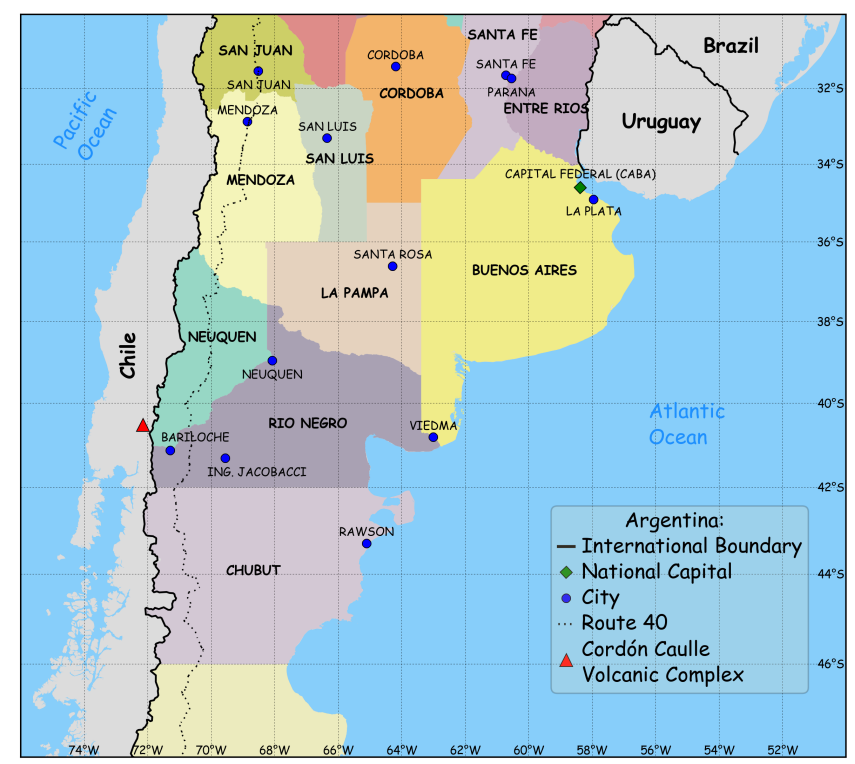

Fig. 2. Map of central-southern Argentina showing the provinces and localities mentioned in the text. The Cordón Caulle Volcanic Complex (CCVC) is indicated by a triangle.

with $d$ and $d_{\mathrm{s}}$ expressed in $\mathrm{mm}$. Given the particle grain size distribution $p(d)$ at each point of the deposit and assuming a discretization in a series of bins $\left(\sum p\left(d_{\text {bin }}\right)=1\right)$, the emission rate of particles of size $d$ can be obtained by summing up the contribution from saltating particles of all sizes equal or larger than $d$ :

$F_{\mathrm{V}}(d)=\sum_{d_{\mathrm{s}}=d}^{d_{\mathrm{s}}=d_{\max }} \frac{\alpha\left(d, d_{\mathrm{s}}\right)}{u_{* t}^{2}(d)} p\left(d_{\mathrm{s}}\right) F_{\mathrm{H}}\left(d_{\mathrm{s}}\right)$,

where $d_{\max }$ is the maximum considered size (typically few hundreds of $\mu \mathrm{m}$ ). Note that, when $u_{*} \gg u_{* t}$, the vertical flux $F_{\mathrm{V}}(d)$ becomes proportional to $u_{*}^{3}$ in both parameterizations Eqs. (8) and (11) (with $F_{\mathrm{H}}$ given by either Eqs. 5 or 6 ).

\subsection{Tested emission schemes}

In this study, we test three different emission schemes (of increasing sophistication) for the case of volcanic ash.

- Emission scheme 1, hereafter referred as the WE scheme. Consists of computing the emission rate using Eq. (7) and a threshold friction velocity $u_{* t}$ independent of particle size (Westphal et al., 1987).

- Emission scheme 2, hereafter referred as the MB scheme. Consists of computing the emission rate using Eq. (8) and the threshold friction velocity $u_{* t}(d)$ using Eq. (2) (Marticorena and Bergametti, 1995; Marticorena et al., 1997).

- Emission scheme 3, hereafter referred as the SH scheme. Consists of computing the emission rate us- ing Eqs. (11) and (5) and the threshold friction velocity $u_{* t}(d)$ using Eq. (3) (Shao et al., 1993; Shao and Leslie, 1997; Shao and Lu, 2000).

Given that these schemes have been developed theoretically and calibrated experimentally for mineral dust rather than for volcanic ash, we multiply the emission rates by a correction factor $\phi$ that will be determined by comparing model values with observations, in our case form the Cordón Caulle 14-18 October 2011 outbreak episode.

\section{The 14-18 October 2011 resuspension event}

The June 2011 eruption from Puyehue-Cordón Caulle Volcanic Complex (CCVC) in Chile blanketed with volcanic ash a vast area of the Argentinean Central Patagonia (Collini et al., 2013). Recurrent ash resuspension events occurred during the following months due to the strong $(\approx 100 \mathrm{~km} / \mathrm{h})$ westerly and southwesterly winds that typically blow over Patagonia during the austral spring (Lässig et al., 1999; Peri et al., 2002). The small villages spread sparsely across the Patagonian steppe (e.g., Ing. Jacobacci in the Río Negro province, see Fig. 2) were heavily impacted by this phenomenon, which hindered ordinary activities and forced inhabitants to remain indoors during the strongest wind episodes (Wilson et al., 2012).

By mid-October 2011, a particularly strong resuspension episode occurred during the passage of a southwestern frontal system crossing northern Patagonia with surface wind speeds of $65-85 \mathrm{kmh}^{-1}$ and maximum gusts of about $95 \mathrm{~km} \mathrm{~h}^{-1}$ measured by Bariloche and Neuquén meteorological stations. As a result, a widespread ash cloud reaching the $850 \mathrm{hPa}$ atmospheric level ( $1.5 \mathrm{~km}$ elevation roughly) was formed and dispersed rapidly east-northeast across Argentina (Damiani, 2011). Impacts occurred at a national level. Main routes in northern Patagonia (e.g., the famous Route 40 linking Bariloche city with the Neuquén province, see Fig. 2) were closed during 15-16 October due to very low visibility and after the occurrence of accidents. This disruption affected the transportation of persons and goods in the southern part of the country. During and after the afternoon of 15 October, the ash cloud reached the provinces of Río Negro, La Pampa, and west of Buenos Aires. In the early morning of 16 October (around 10:00 UTC), a dense ash cloud was clearly visible over the sky of the metropolitan area of Buenos Aires (Ciudad Autónoma de Buenos Aires, CABA), at nearly $1375 \mathrm{~km}$ from CCVC, and a perceptible ash layer was deposited at ground level, blanketing the city, as reported by the meteorological station METARs. The air quality stations of the Government of CABA (GCBA) registered the ash cloud from its arrival and measured a dailyaveraged $\mathrm{PM}_{10}$ level of $252 \mu \mathrm{g} \mathrm{m}^{-3}$. This largely exceeds the US EPA NAAQS (Environmental Protection Agency National Ambient Air Quality Standard) as well as the national legislation standard (law 1356, Government of Buenos Aires) 
limit of $150 \mu \mathrm{g} \mathrm{m}^{-3} \mathrm{PM}_{10}$ concentration for $24 \mathrm{~h}$ exposure. For the first time since the June 2011 CCVC eruption, the national authorities issued warnings regarding transportation in the Buenos Aires province due to the low visibility owing to the presence of suspended ash at low atmospheric levels. Around midday, flights from the Aeroparque Jorge Newbery and Ezeiza international airports, located in CABA, were suspended. Up to 146 flights were canceled on Sunday 16 October alone. The morning after, some scheduled flights began to depart after the cleaning of platforms and runaways but, nevertheless, the main commercial airlines did not resume their operations until Monday 17 October in the afternoon. During this day, the ash cloud covered the south of Uruguay disrupting the Montevideo international airport (40 canceled flights). Flight disruptions affected also the Argentinean airports located in the cities of Córdoba, Mendoza and San Luis until 18 October afternoon because a branch of the ash cloud moved towards these inner provinces making the sky almost invisible.

\section{Modeling strategy}

We modeled the 14-18 October 2011 Cordón Caulle resuspension event using the FALL3D dispersal model (Costa et al., 2006; Folch et al., 2009) coupled offline with the Weather Research and Forecasting (WRF-ARW) meteorological model (Skamarock et al., 2008). FALL3D uses 4D meteorological fields generated offline and volcanological inputs to produce time-dependent variables like airborne ash concentration, ash cloud column load or ground deposit thickness. The new version of the code, FALL3D-7.0 (Folch et al., 2013), includes new capabilities to resolve a "continuum" of sources over a region, as opposed to a single point source or a set of vertical point sources typically considered for eruption columns. As already mentioned in Sect. 2, our modeling strategy builds upon a preliminary eruption simulation run to characterize the deposit (extent, thickness and granulometry at each point) followed by the simulations of resuspension.

\subsection{Deposit characterization}

As a starting point, we ran the WRF-ARW/FALL3D modeling system for the period 4-20 June 2011, during which most deposition of tephra from Cordón Caulle eruption occurred. We considered a Gaussian total grain size distribution (TGSD) discretized in 10 bins ranging from $-1 \Phi$ $(2 \mathrm{~mm})$ to $8 \Phi(4 \mu \mathrm{m})$ and a linear dependency of particle density with diameter (end-member density values of 1000 and $2200 \mathrm{~kg} \mathrm{~m}^{-3}$ ). Note that the largest particles cannot be transported substantially by resuspension but, nonetheless, we considered them because they play a key role in the SH emission scheme (see Eq. 11). FALL3D-7.0 can handle ash aggregation phenomena but not particle disaggregation,

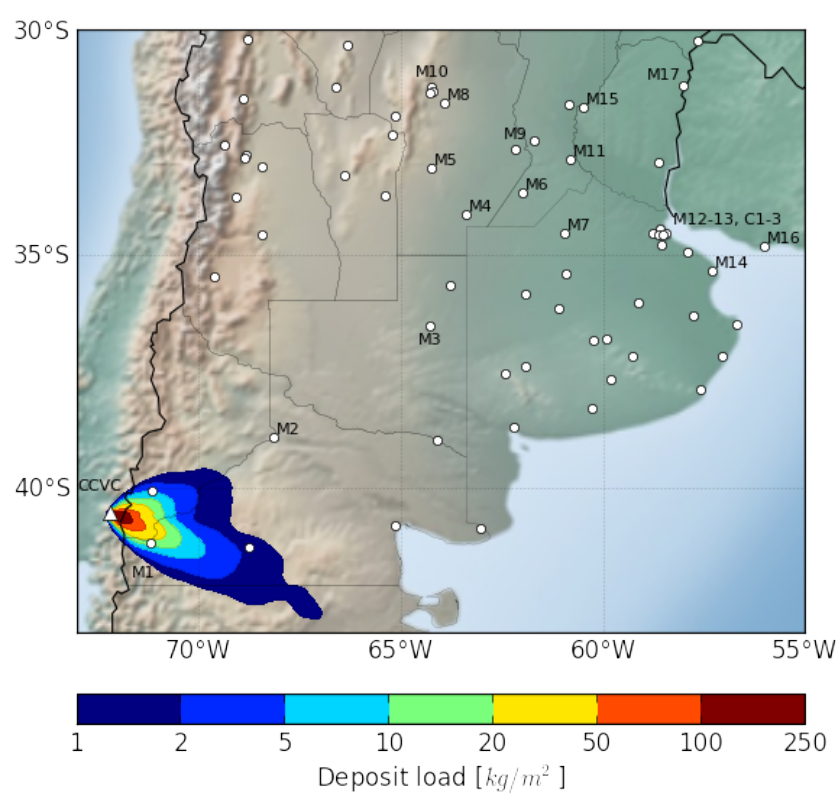

Fig. 3. Simulated deposit load (in $\mathrm{kg} \mathrm{m}^{-2}$ ) used as the initial condition in the simulations of resuspension. The location of the CCVC is indicated by a triangle. Circles show the locations of the ground stations of the Argentinean National Meteorological Service and EPA Air Quality Monitoring Stations Network used to validate the model results.

which typically occurs when (fragile) aggregates impact the ground. For this reason, and because our primary interest is to model subsequent resuspension, particle aggregation was not considered for the deposit simulation. This introduces some uncertainty because the real amount of fine particles in the proximal deposit (originally fallen as aggregates and then disaggregated) can be larger than that predicted by the model. Eruption column heights in the model oscillate daily from around $10 \mathrm{~km}$ a.s.l. (above sea level) down to less than $3 \mathrm{~km}$ a.s.l. by 20 June 2011 (Collini et al., 2013). A comparative study between modeled deposit and field observations can be found in Osores et al. (2012). Fig. 3 shows the modeled deposit that we consider as the potential source area for resuspension. Note that, as observed in the field (see Collini et al., 2013), the main deposition lobe is directed southeast.

\subsection{Meteorological driver and emission schemes}

We used the modeled deposit to initialize the resuspension simulations using a WRF-ARW run from 14-18 October 2011 as the meteorological driver. This WRF-ARW run uses $0.5^{\circ}$ Global Forecast System (GFS) analysis and forecasts supplied by the National Centers for Environmental Prediction (NCEP) of the National Oceanic and Atmospheric Administration (NOAA) as initial and boundary conditions. The WRF-ARW model was configured with a horizontal resolution of $12 \mathrm{~km}, 38$ vertical levels, the Ferrier scheme for microphysics, the Rapid Radiative Transfer Model (RRTM) for 


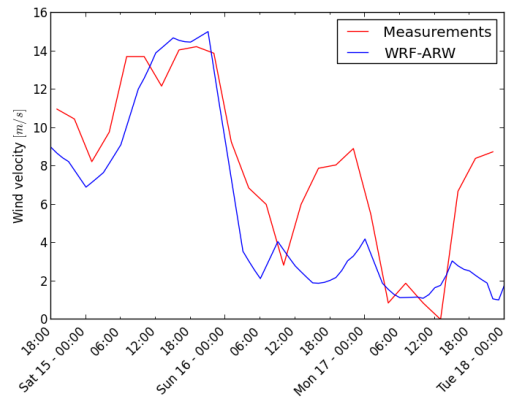

(a) M1 station

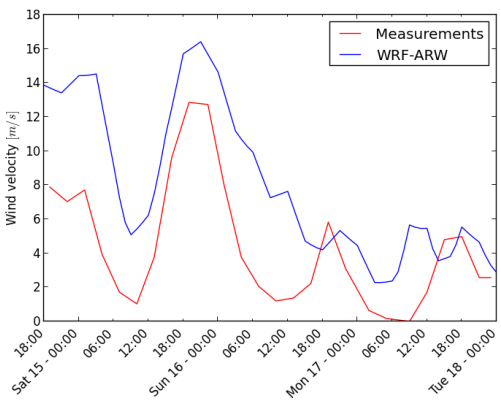

(b) M2 station

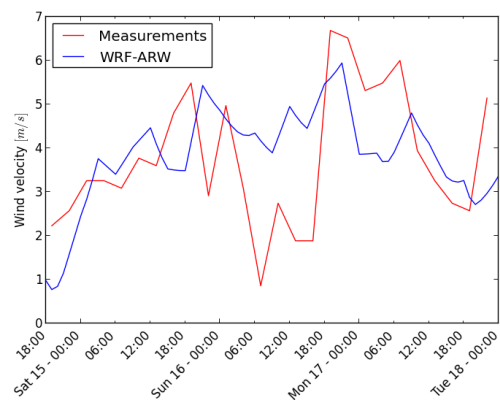

(c) M13 station

Fig. 4. Comparison between WRF-ARW wind surface velocity (blue lines) and measurements (red lines) at 3 different meteorological stations (see Fig. 3 and Table 1): (a) M1 in Bariloche, (b) M2 in Neuquén and (b) M13 in Buenos Aires. Measurements were averaged every $3 \mathrm{~h}$ to match the WRF-ARW time output resolution.

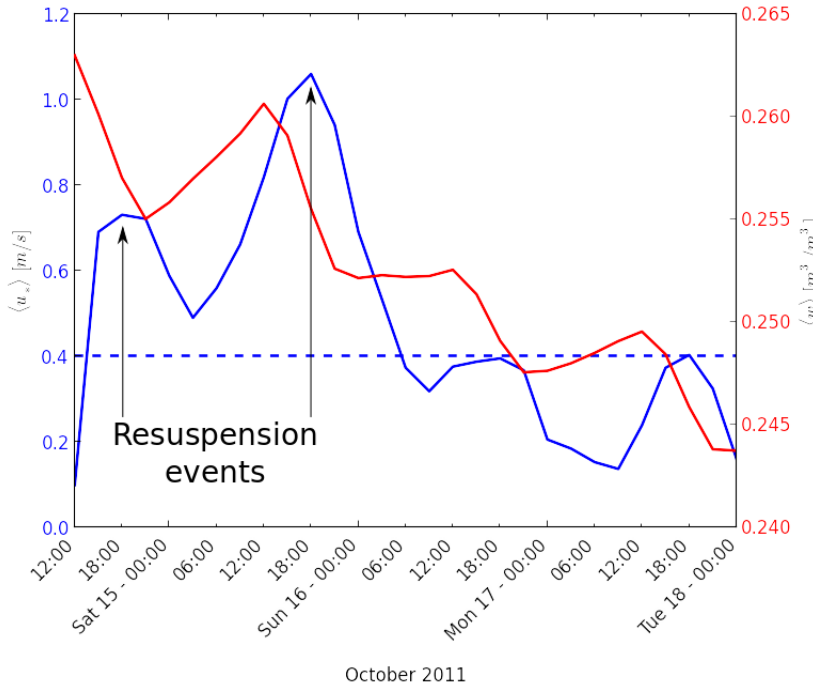

(a)

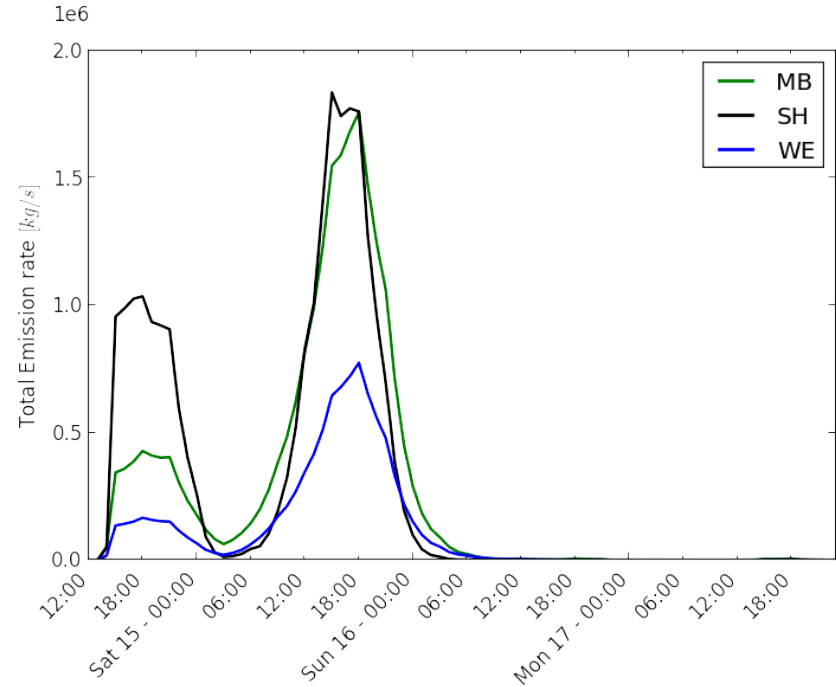

October 2011

(b)

Fig. 5. (a) WRF-ARW friction velocity (blue, left axis) and soil moisture (red, right axis) spatially averaged over the deposit along the period 14-18 October 2011. The discontinuous red line at $u_{*}=0.4 \mathrm{~m} \mathrm{~s}^{-1}$ is shown for reference. (b) Ash emission rate (integrated over the deposit) for the three different emission schemes considering the soil moisture correction on the threshold friction velocity: WE (assuming $u_{* t s}=0.25 \mathrm{~m} \mathrm{~s}^{-1}$ ), MB and SH. Note how two resuspension events, a minor on 14 October at 18:00 UTC and a major $24 \mathrm{~h}$ later, are clearly predicted by all the emission schemes.

long-wave radiation, the Dudhia model for shortwave radiation, the NOAH land surface model, the Betts-Miller-Janjic scheme for convection, and the Mellor-Yamada-Janjic for the planetary boundary layer. The computational domain on the inner WRF-ARW nest spanned between $21^{\circ}-48^{\circ} \mathrm{S} ; 30^{\circ}-$ $90^{\circ} \mathrm{W}$. For illustrative purposes, Fig. 4 compares the WRFARW predicted wind velocities (first model layer, $10 \mathrm{~m}$ above ground) with measurements at three different stations located at Bariloche (M1, 108 km from CCVC), Neuquén (M2, $386 \mathrm{~km}$ from CCVC) and Buenos Aires (Aeroparque airport, M13, $1379 \mathrm{~km}$ from CCVC). Note how two different velocity peaks, responsible for two resuspension events, are clearly visible at M1 and M2. The predictions of WRFARW at station M13 on CABA show the largest discrepancy during 16 October, where differences of up to $4 \mathrm{~m} \mathrm{~s}^{-1}$ exist, concurrently with the plume arrival at CABA. In our opinion, this discrepancy might be due to the Río de la Plata breeze effects not well resolved by the NWP model.

Figure 5 shows the emission rate integrated over the deposit as predicted by the three emission schemes over the 14-18 October 2011 period. Two major resuspension events are evident, the first starting on 14 October at around 18:00 UTC and the second, more intense, starting $24 \mathrm{~h}$ later. Note in Fig. 5a how these events coincide with values of $\left\langle u_{*}\right\rangle$ 


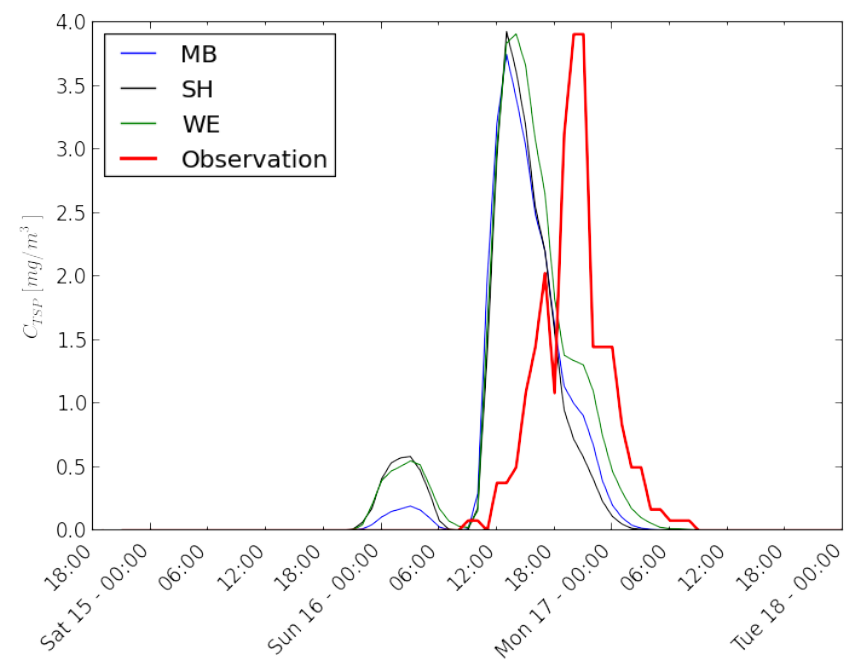

Fig. 6. Results for total suspended particle concentration (in $\mathrm{mg} \mathrm{m}^{-3}$ ) at the M13 meteorological station after applying the correction factor $\phi$ to the different emission schemes. The resulting values for $\phi$ are given in Table 2 .

(spatially averaged $u_{*}$ ) above $0.4 \mathrm{~m} \mathrm{~s}^{-1}$ approximately. In the MB and SH schemes, $u_{* t}$ results from emission model parameterizations, whereas in the WE scheme this quantity is an input to be defined (see Eq. 7). Based on this previous analysis we set $u_{* t s}=0.25$ for the WE scheme that, once corrected by moisture, results in values of $u_{* t} \approx 0.4 \mathrm{~m} \mathrm{~s}^{-1}$. This agrees well with the value of $0.4 \mathrm{~m} \mathrm{~s}^{-1}$ used by Leadbetter et al. (2012) for Eyjafjallajökull in Iceland.

\subsection{Ash transport modeling}

For the resuspension runs, we set a FALL3D-7.0 domain spanning between $30^{\circ}-46^{\circ} \mathrm{S}$ and $49^{\circ}-73^{\circ} \mathrm{W}$ with a horizontal model resolution of $0.1^{\circ}$ and 14 vertical levels ranging from 10 to $4000 \mathrm{~m}$ above terrain (model layer thickness increases gradually in order to have finer resolution within the atmospheric boundary layer, where the ash cloud was mostly confined). The ash emission schemes in FALL3D7.0 assume that the resuspended ash is distributed uniformly along the vertical up to a maximum height fixed by the user (250 m a.g.l. (above ground level) in our case). Particle granulometry changes at each deposit grid point, as determined by interpolating results of the preliminary eruption simulation. For resuspension, we consider the same 10 particle bins but fix the maximum size of particles that can be resuspended to $250 \mu \mathrm{m}$. This allows 7 particle classes to be resuspended and transported. However, larger particles have to be considered because they influence the emission rate in the SH scheme, although we verified that these cannot travel significant distances. Finally, in order to perform the evaluation of the kinematic turbulent fluxes, the diagonal components of the eddy diffusivity tensor in FALL3D have been parameterized using the similarity theory option for the ver- tical component and the CMAQ (Community Multiscale Air Quality) modeling system for the horizontal diffusion (Byun and Schere, 2006).

\subsection{Model calibration}

Our first quantitative comparisons indicated that, in most cases, the simulations overestimated observed surface particle concentrations. There might be multiple reasons for this, including (1) a poor characterization of the deposit, (2) the non-consideration of the surface roughness in the computation of the threshold friction velocity, (3) overestimation of the friction velocity by WRF-ARW or, (4) the inaccuracy of dust emission schemes when applied to volcanic ash. In order to calibrate the emission rates we considered observations made at the M13 meteorological station (see Table 1 for location information). We determined the correction factor $\phi$ for each emission scheme fitting simulation results to observations at this particular station. Results are shown in Fig. 6 and Table 2. Note that $\phi>1$ for the SH scheme and $\phi<1$ for $\mathrm{WE}$ and $\mathrm{MB}$, meaning that the original $\mathrm{SH}$ formulation underestimated source strength whereas WE and MB overestimated. Although the factor $\phi$ was specifically determined from measurements at CABA, the value found was consistent with observations in the other meteorological stations, except for those in the deposit region (see Sect. 6.2).

\section{Results and model validation}

\subsection{Comparison with space-based measurements}

In order to have a first qualitative verification of model results we used images from the Moderate Resolution Imaging Spectroradiometer (MODIS) sensor on-board the AQUA/TERRA satellites using the brightness temperature difference (BTD). The BTD algorithm, also known as the split window technique (Prata, 1989), computes the difference of brightness temperatures (derived from the inverse Plank's function) between the 10.7 and $12 \mu \mathrm{m}$ frequency bands. Given the reverse absorption of volcanic ash particles (negative BTD), the technique allows for discrimination between meteorological and volcanic ash clouds. The efficiency of detection increases when the ash cloud is not opaque, has low water/ice contents, and contains small particles (Prata et al., 2001). Additionally, we considered volcanic ash advisories (VAAs) issued by the Buenos Aires VAAC. These are text messages that identify the observed and forecasted positions of ash clouds (ICAO, 2011). In particular, we used volcanic ash graphics (VAGs), a graphical depiction of the VAAs showing the edges of the polygons encompassing the ash cloud location. VAAs and VAGs from the Buenos Aires VAAC were based on observations from GOES-12 (Geostationary Operational Environmental Administration) and NOAA-19 satellites (METAR and airline pilot reports were considered in some cases). 
Table 1. Location and altitude information of the stations used for the ground observation comparisons. Meteorological stations (from M1 to M17) provide visibility and wind velocity measurements. Air quality stations (from $\mathrm{C} 1$ to $\mathrm{C} 3$ ) provide direct measurements of PM 10 concentration at CABA. All stations belong to Argentina, except for M16 located in Uruguay.

\begin{tabular}{|c|c|c|c|c|c|c|}
\hline $\begin{array}{l}\text { Station } \\
\text { ID }\end{array}$ & $\begin{array}{l}\text { Station } \\
\text { Name }\end{array}$ & Location & $\begin{array}{l}\text { Latitude } \\
\text { (o) }\end{array}$ & $\begin{array}{l}\text { Longitude } \\
\text { (o) }\end{array}$ & $\begin{array}{l}\text { Altitude } \\
\text { (m) }\end{array}$ & $\begin{array}{l}\text { Distance to } \\
\text { CCVC }(\mathrm{km})\end{array}$ \\
\hline M1 & Bariloche & Río Negro & -41.15 & -71.17 & 845 & 108 \\
\hline M2 & Neuquén & Neuquen & -38.95 & -68.13 & 270 & 386 \\
\hline M3 & Santa Rosa & La Pampa & -36.57 & -64.27 & 190 & 815 \\
\hline M4 & Laboulaye & Córdoba & -34.13 & -63.37 & 136 & 1053 \\
\hline M5 & Río Cuarto & Córdoba & -33.12 & -64.23 & 420 & 1084 \\
\hline M6 & Venado Tuerto & Santa Fe & -33.67 & -61.97 & 112 & 1182 \\
\hline M7 & Junín & Buenos Aires & -34.55 & -60.92 & 82 & 1192 \\
\hline M8 & Pilar & Córdoba & -31.67 & -63.88 & 338 & 1233 \\
\hline M9 & Marcos Juárez & Córdoba & -32.70 & -62.15 & 110 & 1246 \\
\hline M10 & Córdoba & Córdoba & -31.32 & -64.22 & 484 & 1248 \\
\hline M11 & Rosario & Santa Fe & -32.92 & -60.78 & 25 & 1319 \\
\hline M12 & Ezeiza & Buenos Aires & -34.82 & -58.53 & 20 & 1355 \\
\hline $\mathrm{C} 1$ & Centenario & CABA & -34.61 & -58.43 & 27 & 1376 \\
\hline M13 & Aeroparque & CABA & -34.57 & -58.42 & 6 & 1379 \\
\hline $\mathrm{C} 2$ & Córdoba & CABA & -34.60 & -58.39 & 35 & 1379 \\
\hline C3 & La Boca & CABA & -34.63 & -58.37 & 11 & 1380 \\
\hline M14 & Punta Indio & Buenos Aires & -35.37 & -57.28 & 16 & 1423 \\
\hline M15 & Paraná & Entre Ríos & -31.78 & -60.48 & 74 & 1428 \\
\hline M16 & Carrasco & Montevideo & -34.83 & -56.01 & 32 & 1551 \\
\hline M17 & Concordia & Entre Ríos & -31.30 & -58.02 & 35 & 1633 \\
\hline
\end{tabular}

Table 2. Characteristic quantities for each emission scheme. The correction factor $\phi$ is adjusted to match the maximum measured concentration of $C_{\mathrm{TSP}}=3.91 \mathrm{mg} \mathrm{m}^{-3}$ at the M13 station. The total emitted mass, mean $\left(\left\langle e_{i}\right\rangle\right)$ and root mean square $\left(\sqrt{\left\langle e_{i}^{2}\right\rangle}\right)$ of residuals at all stations (see Sect. 6.2) are also reported. These can be considered a measure of model to data bias and error respectively.

\begin{tabular}{lrrr}
\hline Scheme & WE & MB & SH \\
\hline$\phi$ & 0.10 & 0.10 & 17 \\
\hline Total emission $\left(\times 10^{10} \mathrm{~kg}\right)$ & 3.3 & 7.7 & 8.5 \\
$\mathrm{PM}_{100}$ emission $\left(\times 10^{10} \mathrm{~kg}\right)$ & 2.4 & 3.7 & 8.5 \\
$\mathrm{PM}_{20}$ emission $\left(\times 10^{10} \mathrm{~kg}\right)$ & 1.4 & 0.26 & 0.012 \\
$\mathrm{PM}_{10}$ emission $\left(\times 10^{10} \mathrm{~kg}\right)$ & 0.95 & $\sim 0^{-4}$ & $\sim 10^{-5}$ \\
$\left\langle e_{i}\right\rangle$ & 0.27 & 0.38 & 1.07 \\
$\sqrt{\left\langle e_{i}^{2}\right\rangle}$ & 1.8 & 2.1 & 3.2 \\
\hline
\end{tabular}

Figure 7 compares remote sensing observations and simulation results. The VAG polygons have been superimposed to the FALL3D predicted column mass at the appropriate times for both MB and SH schemes. The model predicts the formation and evolution of the cloud matching the satellite data, and shows how the ash located in northern Patagonia is transported towards the east and northeast reaching the coastal areas few hours after the passage of the frontal system. A large portion of central Argentina, the Río de La Plata region and southern Uruguay are affected. Note in Fig. 7a how the emission of ash starts shortly after the simulation begins, as expected from our previous analysis (see Fig. 5). The larger area of the VAG polygon in Fig. 7a is explained by the occurrence of a previous minor resuspension event, which was detected and reported by the VAAC. This event was partially modeled because we considered a model spin-up of $6 \mathrm{~h}$.

In general, we found a good qualitative agreement between model results and BTD images. The results of the different schemes are similar, although the SH scheme gives higher concentrations close to the source region. It is interesting to note that, when the simulated cloud passes over the northeast of the Buenos Aires province (between 16 October at 19:00 UTC and 17 October at 01:00 UTC), the cloud is shifted ahead of the observed polygon (see Fig. $7 \mathrm{~d}$ and e). These differences in cloud arrival times may be explained if one considers that WRF-ARW overpredicts wind velocities during this period (see Fig. 4c). Finally, it is worth noting that the little VAG triangle near the CCVC vent in Fig. 7d and e does not correspond to any resuspension phenomenon but reflects minor eruptive events from the CCVC remaining at that time.

\subsection{Comparison with ground-based measurements}

In this section we compare ground measurements of total suspended particulate matter concentration and $\mathrm{PM}_{10}$ (denoted by $C_{\mathrm{TSP}}$ and $C_{\mathrm{PM}_{10}}$, respectively) with the FALL3D 

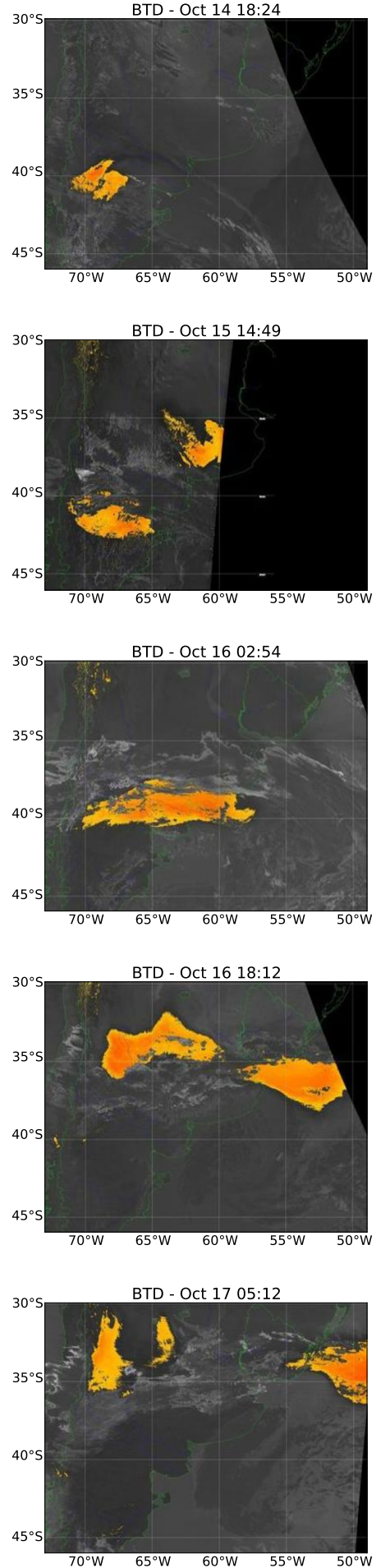

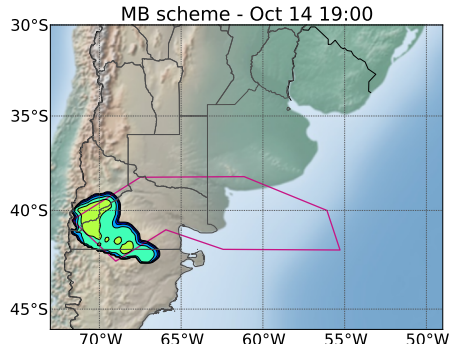

(a)

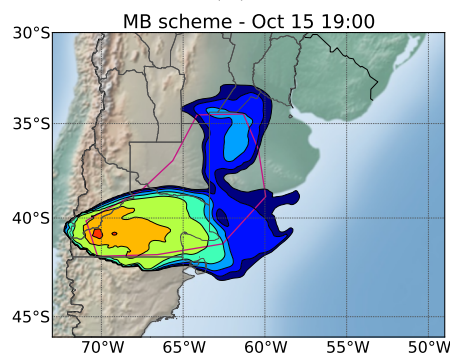

(b)

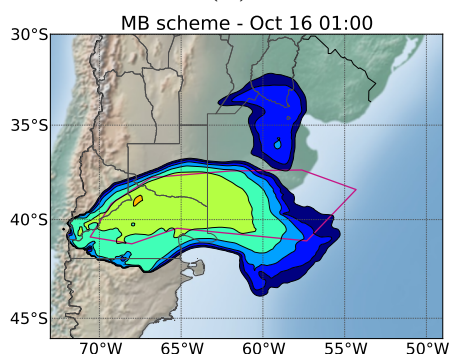

(c)

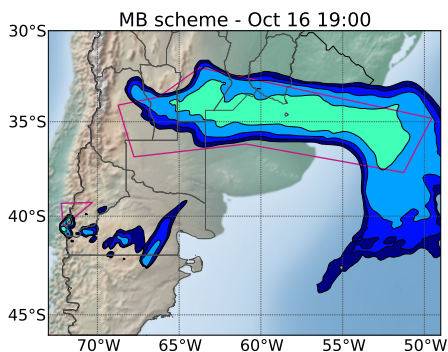

(d)

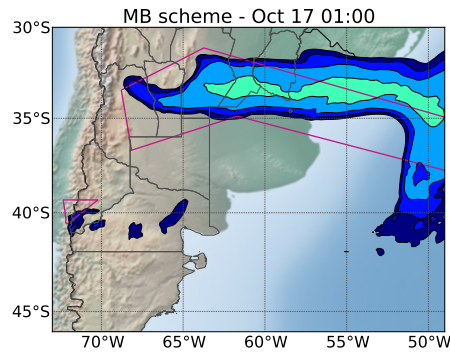

(e)
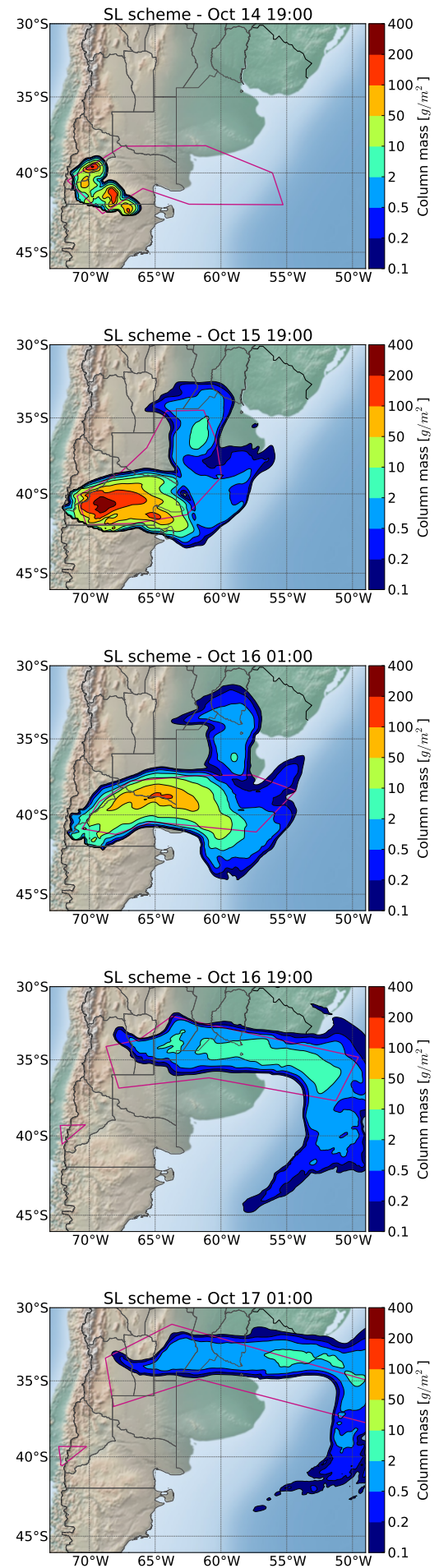

Fig. 7. Comparison between remote sensing observations and simulation results. The first column shows the MODIS images processed with the BTD algorithm. The second and third columns show FALL3D-7.0 results for the total cloud mass per unit area (vertical integration of concentration) using the MB and SH emission schemes respectively. On these pictures, the polygons of the VAG issued by the Buenos Aires VAAC are superimposed for reference. The VAG times in UTC are (a) 19:28 on 14 October, (b) 19:28 on 15 October, (c) 01:28 on 16 October, (d) 19:28 on 16 October and (e) 01:15 on 17 October. Note how the presence of a band of middle and high altitude clouds impedes the complete visualization of the cloud by the satellite. 


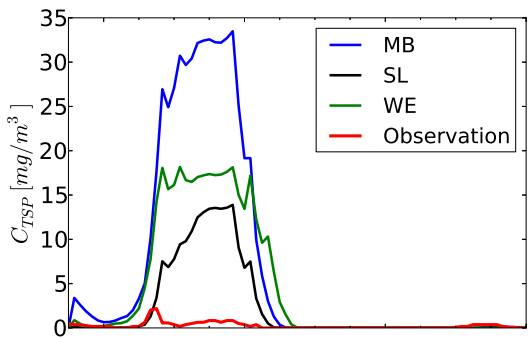

(a) M1

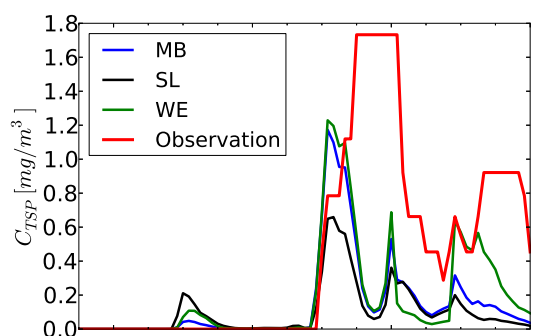

(d) M5

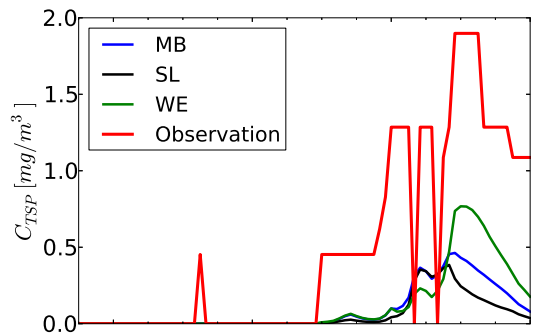

(g) M8

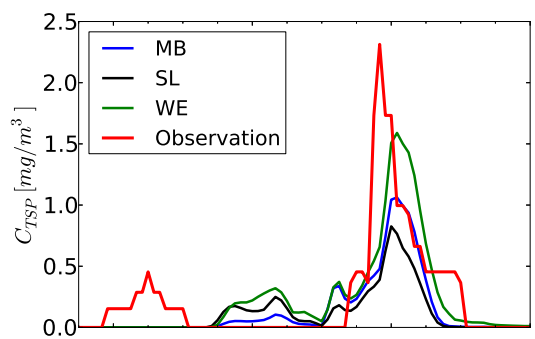

(j) M11

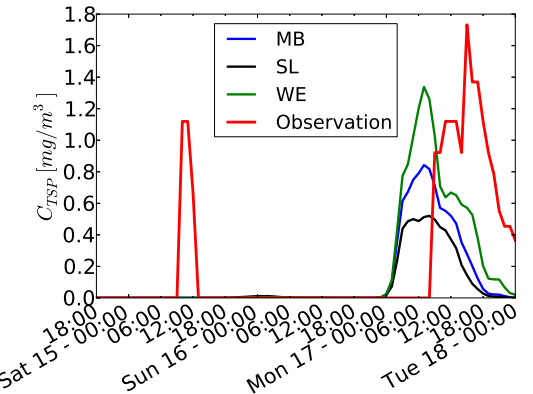

(m) M15

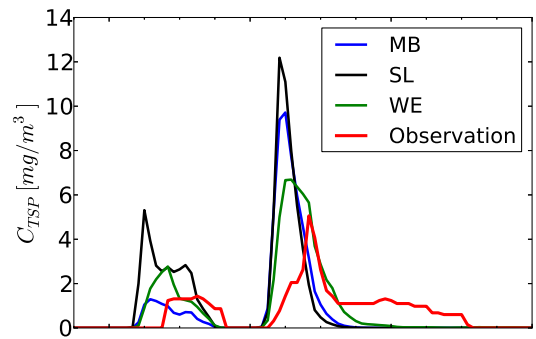

(b) M3

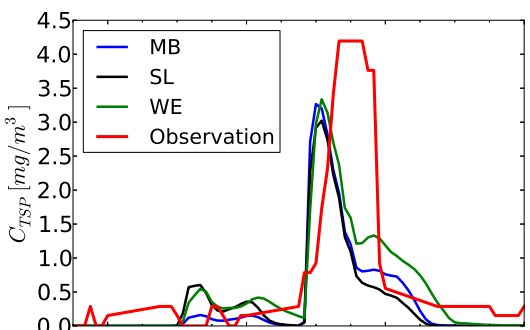

(e) M6

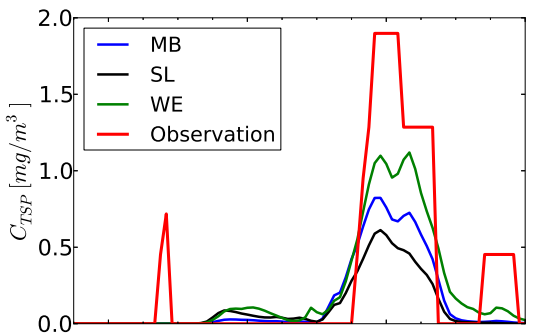

(h) M9

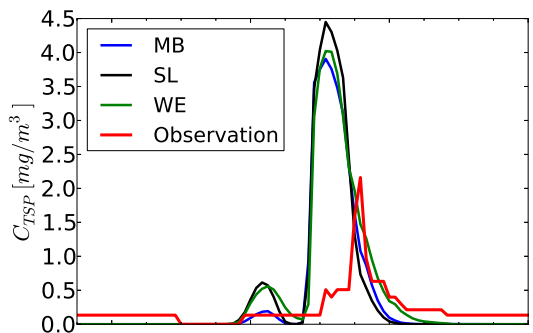

(k) M12

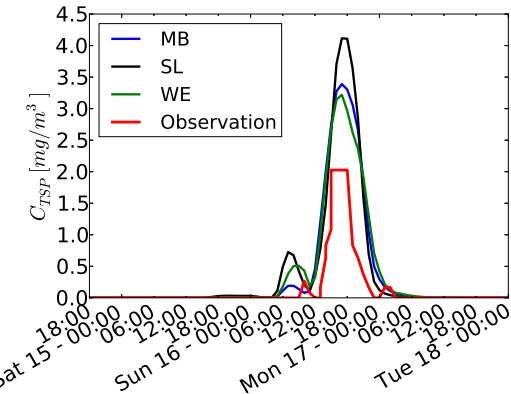

(n) M16

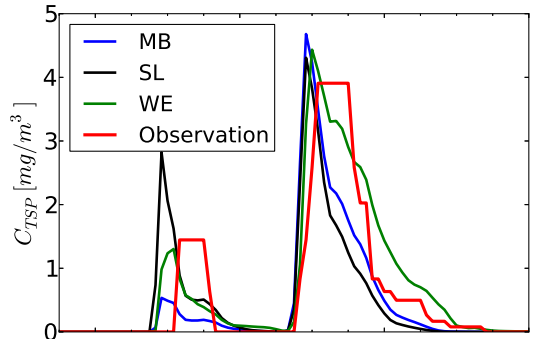

(c) M4

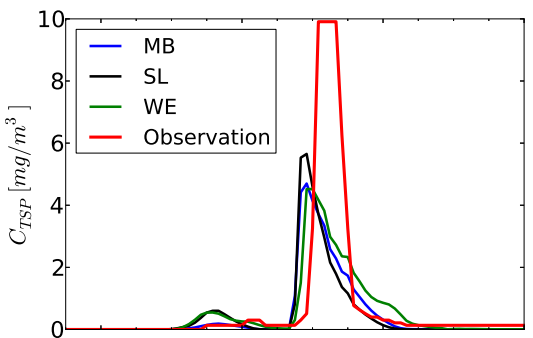

(f) $\mathrm{M} 7$

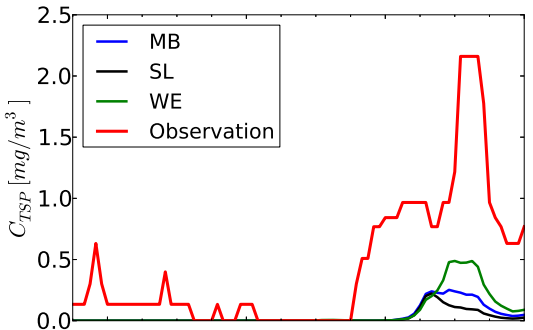

(i) M10

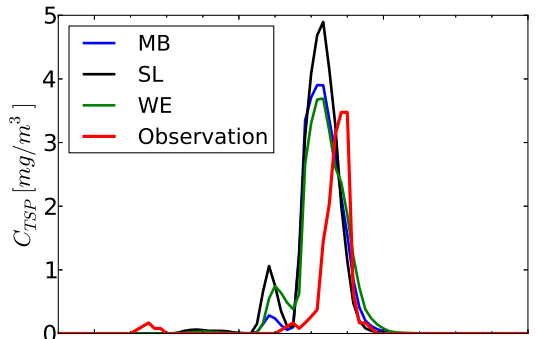

(1) M14

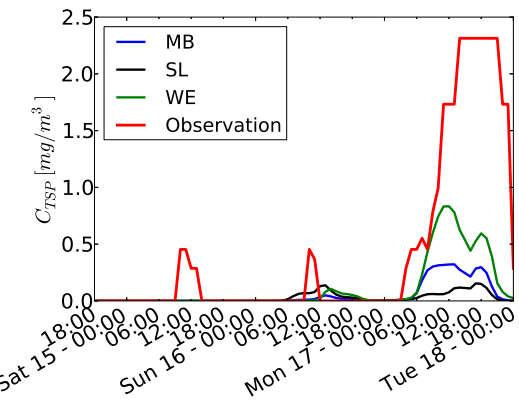

(o) M17

Fig. 8. Comparison between $C_{\mathrm{TSP}}$ (in $\mathrm{mg} \mathrm{m}^{-3}$ ) computed using the three different emission schemes and measurements at 15 different stations. At stations M3 and M4, the two concentration peaks caused by the two resuspension events are clearly visible. In other cases, only the second event can be identified. Other small maxima correspond to different atmospheric phenomena like mist (e.g., the peak recorded on 15 October at station M11, located in Rosario). 


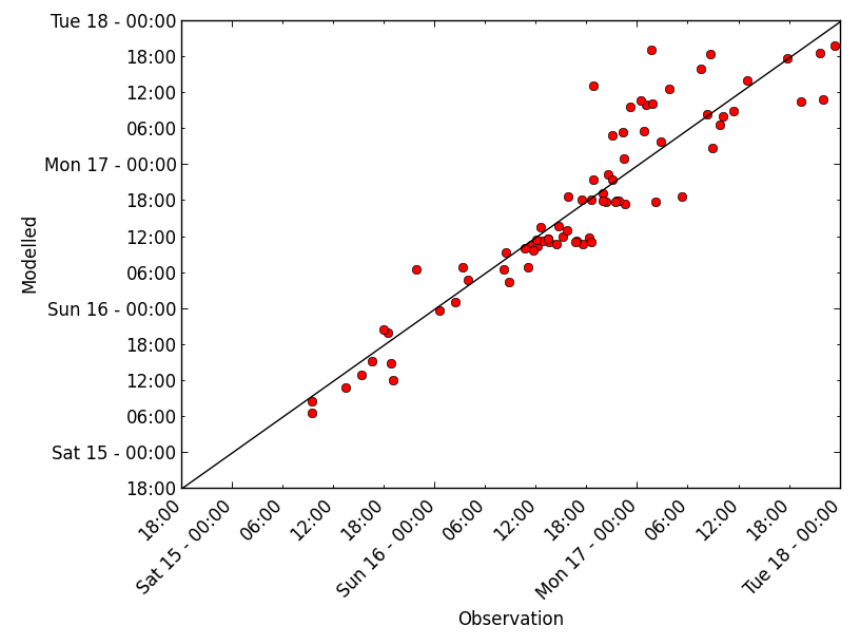

Fig. 9. Comparison between modeled and observed cloud arrival times at the considered stations. Note that model arrival times tend to be slightly ahead of the observed during 17 October, presumably because WRF-ARW overestimates wind velocities. Results are shown only for the WE case, but similar results are observed for the $\mathrm{MB}$ and $\mathrm{SH}$ schemes.

values at the first model layer ( $10 \mathrm{~m}$ above ground level). To this purpose, we used information of visibility, wind speed and direction, and present and past weather phenomena reported in the meteorological message SYNOP (surface synoptic observations) and METAR (Meteorological Aerodrome Report) issued by the stations of the Argentinean National Meteorological Service network and the National Direction of Meteorology of Uruguay (see Fig. 3 and Table 1). The SYNOP is a numerical code (called FM-12 by WMO) used for reporting weather observations made by manned and automated weather stations. We used the visibility observations to yield an estimation of the TSP (total suspended particle) concentration using the following empirical relationship (Shao et al., 2003):

$C_{T S P}= \begin{cases}3802.29 D^{-0.84} & D<3.5 \mathrm{~km} \\ \exp (-0.11 D+7.62) & D \geq 3.5 \mathrm{~km},\end{cases}$

where $C_{\mathrm{TSP}}$ is the TSP concentration (in $\mu \mathrm{g} / \mathrm{m}^{3}$ ) and $D$ is the visibility in $\mathrm{km}$. Besides this data, we also considered measurements of respirable suspended particulate matter $\left(\mathrm{PM}_{10}\right)$ from the EPA Air Quality Monitoring Stations Network (GCBA, 2013). This network consist of three stations located at the northeast $(\mathrm{C} 1)$, downtown $(\mathrm{C} 2)$, and southwest (C3) of CABA. The instruments installed at these stations are the Thermo Model FH62 C14, which continuously measure the mass concentration of particulate utilizing a beta rays attenuation technique. The instruments meet US and International Particulate Monitoring Regulations and are US EPA certified to agree with the international air quality regulations. In the measurements, we subtracted a background value of $32 \mu \mathrm{g} \mathrm{m}^{-3}$, corresponding to the averaged anthro- pogenic contribution recorded in October 2010, in order to estimate the contribution owing to the presence of ash. Additionally, we tried also other sources of data like LIDAR from CEILAP at Villa Martelli, province of Buenos Aires, and raw and processed data from the AERONET network but, because of the presence of clouds, we did not have goodquality data during the considered period.

Figure 8 shows a comparison between simulated $C_{\text {TSP }}$ using the three different schemes and observations at 15 different stations. As observed from the figure, best quantitative agreement is obtained for stations registering the cloud arrival on 16 October (e.g., M4, M6 or M7). In contrast, for far-field stations (e.g., M10 or M17) where the plume arrived on 17 October, the model correctly predicts the arrival time but underestimates the observed values by a factor of 3-5. Conversely, for the stations close to the emission points (e.g., M1 at Bariloche or M2 at Neuquén, not shown) all the emission schemes overestimate substantially.

In order to evaluate if the cloud arrival times were correctly predicted by the model, we defined a characteristic event time as the time when $C_{\text {TSP }}$ reaches half of its maximum value. The comparison between simulated and observed characteristic event times shows good agreement, as observed in Fig. 9 for the WE scheme. Because the arrival time is mainly controlled by the meteorological model, characteristic event times given by the other two schemes were similar.

Figure 10 compares modeled and observed maxima of $C_{\text {TSP }}$ (associated with the plume arrival at each station). Although some scattering exists, differences are in general within a factor of 2 (dashed line in Fig. 10). In order to quantify the performance of the different schemes, we define the residual of the $i$ th observation as $e_{i}=\left(C_{\mathrm{m} i}-C_{\mathrm{o} i}\right) / C_{\mathrm{o} i}$, where $C_{\mathrm{m} i}$ and $C_{\mathrm{o} i}$ are the modeled and observed values of $C_{\text {TSP }}$, respectively. The mean $\left(\left\langle e_{i}\right\rangle\right)$ and root mean square $\left(\sqrt{\left\langle e_{i}^{2}\right\rangle}\right)$ of residuals are reported in Table 2 (note that $\left\langle e_{i}\right\rangle \neq$ 0 is an indicator of model bias and $\left\langle e_{i}^{2}\right\rangle$ quantifies the error). As shown in Fig. 10, $C_{\mathrm{TSP}}$ at points where the plume arrived on 17 October (triangles) are clearly underestimated by the model, contributing with negative residuals. From values in Table 2 we conclude that, for this particular episode, the $\mathrm{WE}$ and MB schemes give similar results, with WE showing the lower bias and error. In contrast, the SH scheme tends to overestimate $C_{\text {TSP }}$ (higher mean residuals) and shows larger differences with observations. Additionally, and regarding $\mathrm{PM}_{10}$ concentration, we observed that $\mathrm{MB}$ and $\mathrm{SH}$ widely underestimate measurements in $\mathrm{CABA}$ (stations $\mathrm{C} 1$, $\mathrm{C} 2$, and $\mathrm{C} 3$ ) whereas $\mathrm{WE}$ gives the right order of magnitude. These low values can be attributed to several factors but, in our opinion, are explained by an incorrect prediction of the threshold friction velocity, which in the MB and SH schemes depends on soil moisture provided by WRF-ARW. In fact we also analyzed results using the MB scheme without soil 


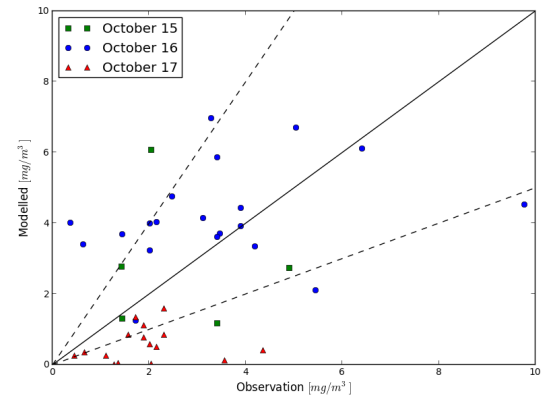

(a) WE

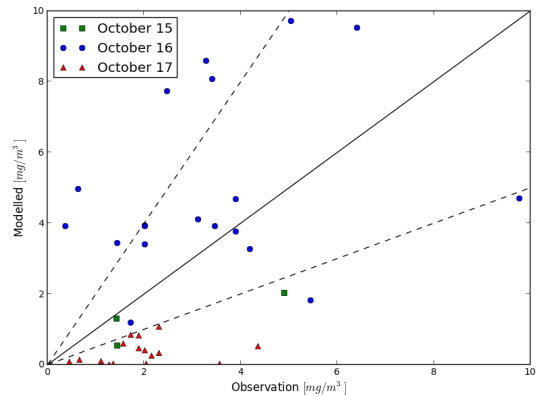

(b) MB

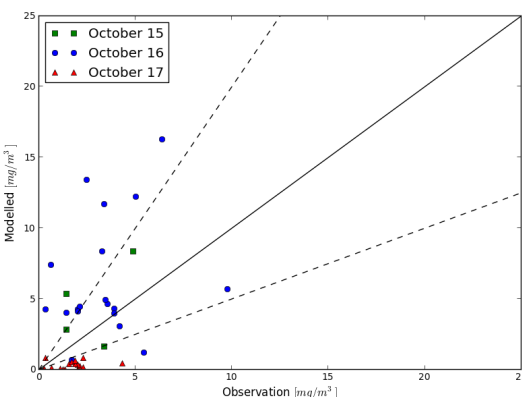

(c) $\mathrm{SH}$

Fig. 10. Modeled versus observed maxima of $C_{\mathrm{TSP}}$ at the different stations and for the 3 emission schemes. Note that during 17 October (red triangles) the model underestimates regardless the emission scheme. However, observations and model estimations of maxima are, in general, within a factor of 2 (dashed lines).

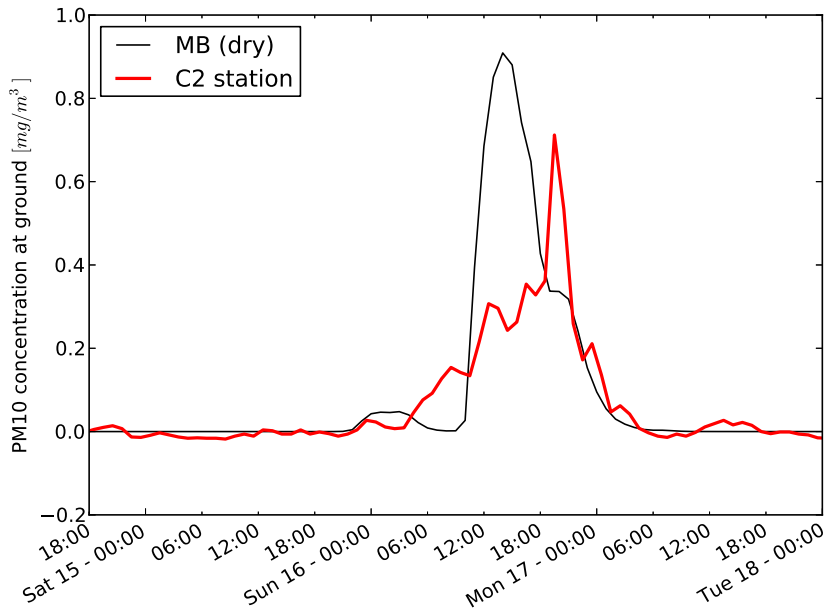

Fig. 11. Observed (red) and modeled $\mathrm{PM}_{10}$ concentration at station $\mathrm{C} 2$ considering dry soil (no soil moisture correction) and the MB scheme.

moisture correction, and found this gives much better results for $\mathrm{PM}_{10}$ concentration in CABA (see Fig. 11).

\section{Conclusions}

We have implemented and tested three different dust emission schemes in the FALL3D-7.0 tephra dispersal model in order to simulate the 14-18 October 2011 ash resuspension events in central Patagonia. The modeling strategy combines a preliminary simulation to characterize the fallout deposit followed by the simulations of resuspension using FALL3D driven offline by WRF-ARW. Even if not specifically developed for volcanic ash, all the emission schemes give very promising results when comparing the simulated clouds with satellite images and the predicted concentrations of $\mathrm{PM}_{10}$ and TSP at ground with measurements at different stations.
The three schemes present a similar qualitative behavior, but differ in the amount of emitted ash. Total resuspended mass is $8.4 \times 10^{10} \mathrm{~kg}$ for $\mathrm{SH} ; 7.7 \times 10^{10} \mathrm{~kg}$ for $\mathrm{MB}$ and $3.3 \times$ $10^{10} \mathrm{~kg}$ for WE. For comparison, Collini et al. (2013) estimated a total amount of erupted ash mass of $1-5 \times 10^{12} \mathrm{~kg}$ during the period 4-19 June 2011. This amount of mass can give an idea of the hazards and disturbances caused by resuspended ash transported during the period considered in this study.

Remarkably, we find better agreement with observations using the simplest emission scheme (WE), although MB and $\mathrm{SH}$ showed also a good agreement. This result highlights the role of the sensitivity of more complex emission schemes to input parameters. In fact, relevant magnitudes for the source strength in the MB and SH schemes, such as granulometry or soil moisture, were obtained from modeling and are subject to large uncertainties. On the other hand, the simplest WE scheme seems more attractive from an operational point of view given its versatility. For example, an operator could easily set $u_{* t s}$ according to a specific situation in order to match partial observations with model results. Our next research steps are to explore how to better constrain inputs for more sophisticated schemes and to investigate how to improve model accuracy in the near-field areas.

Acknowledgements. This work has been partially funded by the Spanish research project Atmospheric transport models and massive parallelism: applications to volcanic ash clouds and dispersion of pollutants at an urban micro-scale (ATMOST, CGL2009-10244) and the CYTED thematic network Red Iberoamericana para el monitoreo y modelización de cenizas y aerosoles volcánicos y su impacto en infraestructuras y calidad del aire (CYTED, 410RT0392). The WRF-ARW/FALL3D modeling system ran in a server installed at the SMN with funds from the Argentinean project PIDDEF 41/10: Pronóstico del tiempo para estudios de vulnerabilidad e impacto socioeconómico, which also supported partly this research and L. Mingari fellowship. We thank CONAE for postprocessing the MODIS images with the BTD algorithm. We 
also thank María Inés de Casas from GCBA for providing PM $_{10}$ data and M. Suaya from SMN for guidance on observational data. The SMN provided the SYNOP and METAR data sets and Raúl Ródano (Aerolíneas Argentinas) information on flight cancelations. L. Mingari and M. S. Osores thank CONICET and CONAE for their PhD fellowship. Finally, we acknowledge Peter Webley, Larry Mastin and Matthew Hort for their constructive reviews.

Edited by: A. Costa

Reviewed by: P. Webley, L. Mastin, and M. C. Hort

\section{References}

Barsotti, S., Andronico, D., Neri, A., Carlo, P. D., Baxter, P.J ., Aspinall, W. P., and Hincks, T.: Quantitative assessment of volcanic ash hazards for health and infrastructure at Mt. Etna (Italy) by numerical simulation, J. Volcanol. Geotherm. Res., 192, 85-96, 2010.

Baxter, P. J.: Impacts of eruptions on human health, in: Encyclopaedia of Volcanoes, edited by: Siggurdson, H., Academic Press, New York, 1035-1043, 1999.

Bonadonna, C., Folch, A., Loughlin, S., and Puempel, H.: Future developments in modelling and monitoring of volcanic ash clouds: outcomes from the first IAVCEI-WMO workshop on Ash Dispersal Forecast and Civil Aviation (Geneva, Switzerland, 1820 October 2010), Short Scientific Communication, Bull. Volcanol., 74, 1-10, doi:10.1007/s00445-011-0508-6, 2012.

Byun, D. and Schere, K. L.: Review of the governing equations, computational algorithms, and other components of the Models3 Community Multiscale Air Quality (CMAQ) modeling system, Appl. Mechan. Rev., 59, p. 51, 2006.

Collini, E., Osores, M. S., Folch, A., Viramonte, J., Villarosa, G., and Salmuni, G.: Volcanic ash forecast during the June 2011 Cordón Caulle eruption, Natural Hazards, 66, 389-412, doi:10.1007/s11069-012-0492-y, 2013.

Costa, A., Macedonio, G., and Folch, A.: A three-dimensional Eulerian model for transport and deposition of volcanic ashes, Earth Planet. Sci. Lett., 241, 634-647, 2006.

Damiani, G. O.: Metodología implementada por el VAAC BUENOS AIRES en la detección y pronóstico de dispersión de ceniza removilizada desde la superficie, personal communication, 2011

Darmenova, K., Sokolik, I. N., Shao, Y., Marticorena, B., and Bergametti, G.: Development of a physically based dust emission module within the Weather Research and Forecasting (WRF) model: Assessment of dust emission parameterizations and input parameters for source regions in Central and East Asia, J. Geophys. Res., 114, D14201, doi:10.1029/2008JD011236, 2009.

Draxler, R. R., Gillette, D. A., Kirkpatrick, J. S., and Heller, J.: Estimating PM10 air concentrations from dust storms in Iraq, Kuwait, and Saudi Arabia, Atmos. Environ., 35, 4315-4330, 2001.

GCBA: Red de estaciones EPA de monitoreo atmosférico, www. buenosaires.gob.ar/areas/med_ambiente/apra/calidad_amb, 2013.

Fecan, F., Marticorena, B., and Bergametti, G.: Parametrization of the increase of the aeolian erosion threshold wind friction velocity due to soil moisture for arid and semi-arid areas, Ann. Geo- phys., 17, 149-157, 1999,

http://www.ann-geophys.net/17/149/1999/.

Folch, A.: A review of tephra transport and dispersal models: Evolution, current status, and future perspectives, J. Volcanol. Geothermal Res., 235/236, 96-15, 2012.

Folch, A., Costa, A., and Macedonio, G.: FALL3D: a computational model for transport and deposition of volcanic ash, Comput. Geosci., 35, 1334-1342, 2009.

Folch, A., Costa, A., and Macedonio, G.: FALL3D-7.0: User's Manual [on line], August 2013, Available in Web: http://bsccase02. bsc.es/projects/fall3d/Downloads/fall3d-7.0.pdf, 2013.

Gillette, D. A., Fryrear, D. W., Gill, T. E., Ley, T., Cahill, T. A., and Gearhart, E. A.: Relation of vertical flux of PM10 to total aeolian horizontal mass flux at Owens Lake, J. Geophys. Res., 102, 26009-26015, 1997.

Greeley, R. and Iversen, J. D.: Wind as a geological process on Earth, Mars, Venus and Titan, Cambridge planetary science series, 1985.

Guffanti, M., Mayberry, G. C., Casadevall, T. J., and Wunderman, R.: Volcanic hazards to airports, Nat. Hazards, 51, 287-302, 2009.

Hadley, D., Hufford, G. L., and Simpson, J. J.: Resuspension of Relic Volcanic Ash and Dust from Katmai: Still an Aviation Hazard, Wea. Forecasting, 19, 829-840, 2004.

Hincks, T. K., Aspinall, W. P., Baxter, P. J., Searl, A., Sparks, R. S. J., and Woo, G.: Long term exposure to respirable volcanic ash on Montserrat: a time series simulation. Bull. Volcanol., 68, 266-284. doi:10.1007/s00445-005-0006-9, 2006.

Hobbs, P. V., Hegg, D. A., and Radke, L. F.: Resuspension of volcanic ash from Mount St. Helens, J. Geophys. Res., 88, 39193921, 1983.

ICAO: Manual of Aeronautical Meteorological Practice (Doc 8896), 9th edition, 2011.

Iversen, J. D. and White, B. R.: Saltation threshold on Earth, Mars, and Venus, Sedimentology, 29, 111-119, 1982.

Kang, J.-Y., Yoon, S.-C., Shao, Y., and Kim, S.-W.: Comparison of vertical dust flux by implementing three dust emission schemes in WRF/Chem, J. Geophys. Res., 116, D09202, doi:10.1029/2010JD014649, 2011.

Lässig, J. L., Cogliati, M. G., Bastanski, M. A., and Palese, C.: Wind characteristics in Neuquen, North Patagonia, Argentina, Journal of Wind Engineering and Industrial Aerodynamics, 79, 183-199, 1999.

Leadbetter, S. J., Hort, M. C., von Löwis, S., Weber, K., and Witham, C. S.: Modeling the resuspension of ash deposited during the eruption of Eyjafjallajökull in spring 2010, J. Geophys. Res., 117, D00U10, doi:10.1029/2011JD016802, 2012.

Marticorena, B. and Bergametti, G.: Modeling the atmospheric dust cycle: 1. Design of a soil-derived dust emission scheme, J. Geophys. Res., 100, 16415-16430, doi:10.1029/95JD00690, 1995.

Marticorena, B., Bergametti, G., Aumont, B., Callot, Y., N'Doumé, C., and Legrand, M.: Modeling the atmospheric dust cycle 2. Simulation of Saharan dust sources, J. Geophys. Res., 102, 4387 4404, doi:10.1029/96JD02964, 1997

Marticorena, B., Bergametti, G., Gillette, D., and Belnap, J.: Factors controlling threshold friction velocity in semiarid and arid areas of the United States. J. Geophys. Res., 102, 23277-23287, 1997b. 
Osores, M. S., Collini, E. A., Folch, A., and Villarosa, G.: Mejoras en el pronóstico de dispersión y depósito de cenizas volcánicas en Argentina, In: XXVI Reunión Científica de la Asociación Argentina de Geofísicos y Geodestas, AAGG, Tucumán, Argentina, 2012.

Owen, P. R.: Saltation of uniform grains in air, J. Fluid Mech., 20, 225-242, 1964

Peri, P. L. and Bloomberg, M.: Windbreaks in southern Patagonia, Argentina: A review of research on growth models, windspeed reduction, and effects on crops, Agroforestry Systems, 56, 129144, 2002.

Prata, A. J.: Observations of volcanic ash clouds in the $10-12 \mu \mathrm{m}$ window using AVHRR/2 data, Internat. J. Rem. Sens., 10, 751761, 1989.

Prata, A. J., Bluth, G., Rose, B., Schneider, D., and Tupper, A.: Comments on "Failures in detecting volcanic ash from a satellitebased technique", Remote Sensing of Environment, 78, 341-346, 2001.

Shao, Y.: A model for mineral dust emission, J. Geophys. Res., 106, 20239-20254, doi:10.1029/2001JD900171, 2001.

Shao, Y. and Leslie, L. M.: Wind erosion prediction over the Australian continent, J. Geophys. Res.,102, 30091-30105, 1997.

Shao, Y. and Lu, H.: A simple expression for wind erosion threshold friction velocity, J. Geophys. Res., 105, 22437-22443, 2000.

Shao, Y., Raupach, M. R., and Findlater, P. A.: Effect of Saltation Bombardment on the Entrainment of Dust by Wind, J. Geophys. Res., 98, 12719-12726, doi:10.1029/93JD00396, 1993.
Shao, Y., Yang, Y., Wang J., Song Z., Leslie L.M., Dong C., Zhang Z., Lin Z., Kanai Y., Yabuki S., and Chun, Y.: Northeast Asian dust storms: Real-time numerical prediction and validation, J. Geophys. Res., 108, 4691, doi:10.1029/2003JD003667, 2003.

Skamarock, W. C., Klemp, J. B., Dudhia, J., Gill, D. O., Barker, D. M., Duda, M. G., Huang, X-Y, Wang, W., and Powers, J. G.: A description of the advanced research WRF version 3, NCAR technical note, NCAR/TN-475+ STR, 2008.

Thorsteinsson, T., Jóhannsson, J., Stohl, A., and Kristiansen, N. I.: High levels of particulate matter in Iceland due to direct ash emissions by the Eyjafjallajökull eruption and resuspension of deposited ash, J. Geophys. Res., 117, B00C05, doi:10.1029/2011JB008756, 2012.

Westphal, D. L., Toon, O. B., and Carlson, T. N.: A two-dimensional numerical investigation of the dynamics and microphysics of Saharan dust storms, J. Geophys. Res., 92, 3027-3049, 1987.

White, B. R.: Soil Transport by Winds on Mars, J. Geophys. Res., 84, 4643-4651, doi:10.1029/JB084iB09p04643, 1979.

Wilson, T. M., Cole, J. W., Stewart, C., Cronin, S. J., and Johnston, D. M.: Ash storms: Impacts of wind-remobilised volcanic ash on rural communities and agriculture following the 1991 Hudson eruption, southern Patagonia, Chile, Bull. Volcanol., 73, 223239, doi:10.1007/s00445-010-0396-1, 2011.

Wilson, T., Stewart, C., Bickerton, H., Baxter, P., Outes, V., Villarosa, G., and Rovere, E.: Impacts of the June 2011 PuyehueCordón Caulle volcanic complex eruption on urban infrastructure, agriculture and public health, GNS Science Report, 20, 88 pp., 2012. 